\title{
Reseña del libro Globalización, libre comercio y salud
}

Arrivillaga M, Borrero Y, Salcedo JP. Globalización, libre comercio y salud.

Bogotá: Ediciones Aurora; 2014

\section{Por: Helena Espinosa-Restrepo}

doi: 10.11144/Javeriana.rgyps13-27.glcs

\section{Cómo citar esta reseña:}

Espinosa-Restrepo H. Reseña del libro Globalización, libre comercio y salud. Rev. Gerenc. Polít. Salud. 2014; 13(27): 370-372. http://dx.doi.org/10.11144/Javeriana.rgyps13-27.glcs

La Facultad de Medicina de la Universidad Javeriana de Cali lanzó el 10 de abril del 2014 el programa de Maestría de Salud Pública y en el mismo acto tuve el honor de hacer la presentación del libro que a continuación reseño.

El libro Globalización, libre comercio y sa$l u d$, lo considero en su totalidad una obra de mucha riqueza en sus análisis y de gran excelencia técnica y científica. Es indiscutiblemente una obra de consulta para muchos estudiosos interesados en los temas afines a los de salud pública, como son los de política, economía y justicia social. No pretendo detallar los apartes más destacados de cada capítulo porque tomaría mucho tiempo. Lo que quiero es dejar constancia de que absolutamente todos los autores son merecedores de elogios por la documentación que aportan y la calidad de sus análisis. A continuación resumo algunos comentarios y apreciaciones del contenido de esta obra.

La lectura de este excelente libro me hizo sentir "huérfana" para la época que me tocó vivir en Washington, ante los hechos que precedieron y justificaron las reformas del Estado, con las sucesivas reducciones de las 370 políticas y programas de los sectores sociales, reducciones que para la salud fueron fatales.
Me refiero al Consenso de Washington de 1986, y sobre todo a los documentos que produjo el Banco Mundial, como el Informe sobre el desarrollo mundial 1993: Invertir en salud, y los que difundían en seminarios los consultores del Banco Interamericano de Desarrollo (BID). Todos ellos promovían las reformas de los sistemas de salud con énfasis en la privatización y la introducción de las leyes del mercado en la prestación de servicios. El resultado fueron las desafortunadas, injustas e inequitativas reformas de los sistemas de salud en varios de los países de América Latina. Qué bueno hubiera sido contar con análisis como los del libro que nos ocupa para rebatir a los que se dejaron convencer de que las reformas debían seguir los lineamientos del Banco Mundial.

Los diferentes capítulos están interrelacionados de tal forma que forman un tejido cuyos hilos se cruzan. Comentaré sucintamente los capítulos, divididos en cuatro temáticas definidas un poco arbitrariamente: 1) globalización, 2) derechos sociales y de salud, 3) libre comercio y 4) medicamentos.

Es muy satisfactorio ver que los temas de las relaciones entre la globalización y la salud sean objeto de estudios tan serios y profun- 
dos como lo muestran los capítulos que los tratan. Estos documentan el predominio de la globalización financiera, el poder de los mercados, las fuerzas que los impulsan y las consecuencias en los sectores sociales y la vida de los ciudadanos en todo el mundo, en especial en los países más pobres del sur. Obviamente, el énfasis de estos capítulos está puesto sobre el efecto del poder de los grandes capitales que mueven los mercados en el sector de la salud y la privatización de los sistemas de servicios, con el consiguiente agravamiento de las inequidades sociales. La lógica financiera que se impone en las políticas públicas conduce a que el Estado termine siendo regulador y no proveedor, como lo exponen Jorge Iván González, Juan Pablo Salcedo y Marcela Arrivillaga.

El tema de los derechos sociales y el del derecho fundamental de la salud es tratado exhaustivamente por varios autores, los cuales proporcionan un contenido muy erudito sobre los documentos legales, constitucionales y de carácter internacional que soportan la importancia y la necesidad de exigir a los gobiernos el respeto y la garantía de los derechos en un Estado Social de Derecho. También exponen las artimañas y los juegos perversos, diría yo, de los Estados para burlar el cumplimiento de las obligaciones relacionadas con estos derechos. El caso de Colombia es presentado en detalle, así como los aspectos relacionados con el único instrumento de que dispone la gente para exigir sus derechos, como es la "tutela". Los autores Francisco Cortés Rodas, María Esperanza Echeverry, Yadira Eugenia Borrero y Victoria Eugenia Estrada debaten sobre la fundamentación filosófica del derecho a la salud, su justiciabilidad y la construcción del derecho a la salud, partiendo de una globalización desde abajo. Llegamos a la conclusión de que en este país el derecho fundamental de la salud sigue siendo una aspiración, lejos de ser una realidad.
El Libre Comercio y el papel de la Organización Mundial de Comercio (OMC) para que los países poderosos logren conseguir que los pobres firmen los tratados de libre comercio (TLC), con obvias ventajas para los primeros y desventajas para los segundos, son temas abordados en varios capítulos por Luis Alejandro Arévalo y Sara E. del Castillo, con detallada información y sólidos juicios de expertos economistas, legisladores y funcionarios de los sectores de agricultura y salud. En el Foro Mundial Urbano realizado en Medellín en abril de este año, el economista Joseph Stiglitz dijo refiriéndose a los TLC con Estados Unidos: "[...] esos no son tratados de libre comercio, libre sólo es el nombre. Son tratados manejados por el interés de Estados Unidos [...]". Da gran satisfacción que el problema de los desventajosos tratados se acepte que competa en forma importante al sector de la salud y que ya se cuente con excelentes estudios y reflexiones desde la salud pública.

Finalmente, los "medicamentos", como tema que tiene que ver con la globalización, el libre comercio, la equidad y los derechos de los pacientes, está presentado con un gran conocimiento por reconocidos expertos, tales como Steven Orozco, Germán Velásquez y Xavier Seuba. De sus análisis se deduce la desgastante lucha que se ha llevado a cabo, y se sigue llevando, para vencer el injusto tratamiento que se da a los países pobres para que la gente no se muera por falta de medicamentos, porque las barreras impuestas por los países ricos niegan toda posibilidad de producirlos. De igual forma, los autores abordan ampliamente cómo las grandes corporaciones farmacéuticas cuentan con la protección de los gobiernos y de tratados internacionales. La absoluta indiferencia de países poderosos como Estados Unidos y los de Europa trae consecuencias deplorables para la salud de los pacientes de los países 
que no pueden competir con los poderosos productores de medicamentos.

Finalmente, con respecto a dos temas más específicos tratados en sendos capítulos, como son el del envejecimiento en el marco de la globalización, de Deyse Arrubla, y el de la seguridad alimentaria y nutricional amenazada por el TLC en Colombia, de Sara E. del Castillo, se aportan enfoques importantes que es necesario tener en cuenta para la formulación de políticas públicas saludables y planes nacionales que se desarrollen con la integralidad y multisectorialidad necesarias a estos aspectos y no como parte de los sistemas de servicios asistenciales.
Para terminar, quiero afirmar que este libro devela la irresponsabilidad y la hipocresía de los gobiernos para erradicar la injusticia, la falta de equidad y las ambivalencias para satisfacer, desde el sector público, los derechos humanos sociales y económicos, en especial el derecho a la salud de la gente de nuestros países. En conclusión, recomendamos que este texto que se presenta hoy ante la comunidad académica de la Universidad Javeriana de Cali, se difunda para que sea leído y apreciado no solo en el contexto actual de Colombia, sino también en toda la región de América Latina, y que forme parte de las bibliotecas de las instituciones formadoras en salud pública. 